\title{
A Study on DLC Tool Coating for Deep Drawing and Ironing of Stainless Steel
}

\author{
Üstünyagiz, Esmeray; Hafis Sulaiman, Mohd ; Christiansen, Peter; Nielsen, Chris V.; Bay, Niels
}

Published in:

Key Engineering Materials

Link to article, DOI:

10.4028/www.scientific.net/KEM.767.181

Publication date:

2018

Document Version

Peer reviewed version

Link back to DTU Orbit

Citation (APA):

Üstünyagiz, E., Hafis Sulaiman, M., Christiansen, P., Nielsen, C. V., \& Bay, N. (2018). A Study on DLC Tool Coating for Deep Drawing and Ironing of Stainless Steel. Key Engineering Materials, 767, 181-188.

https://doi.org/10.4028/www.scientific.net/KEM.767.181

\section{General rights}

Copyright and moral rights for the publications made accessible in the public portal are retained by the authors and/or other copyright owners and it is a condition of accessing publications that users recognise and abide by the legal requirements associated with these rights.

- Users may download and print one copy of any publication from the public portal for the purpose of private study or research.

- You may not further distribute the material or use it for any profit-making activity or commercial gain

- You may freely distribute the URL identifying the publication in the public portal 


\title{
A Study on DLC Tool Coating for Deep Drawing and Ironing of Stainless Steel
}

\author{
Esmeray Üstünyagiz ${ }^{1, a^{*}}$, Mohd Hafis Sulaiman ${ }^{2, b}$, Peter Christiansen ${ }^{1, c}$, \\ Chris V. Nielsen ${ }^{1, d}$ and Niels Bay ${ }^{1, e}$ \\ ${ }^{1}$ Department of Mechanical Engineering, Technical University of Denmark, 2800 Kgs. Lyngby, \\ Denmark \\ ${ }^{2}$ Mechanical Eng. Programme, Universiti Malaysia Perlis, 02600 Arau, Perlis, Malaysia \\ aesustu@mek.dtu.dk, bhafissulaiman@unimap.edu.my, ${ }^{c}$ petc@mek.dtu.dk, dcvni@mek.dtu.dk, \\ enbay@mek.dtu.dk
}

Keywords: Metal forming, tribology, DLC, coating, simulative testing.

\begin{abstract}
The trend in metal forming tribology is to develop new tribo-systems including new lubricants, tool materials and tool coatings in order to substitute environmentally hazardous lubricants by environmentally friendly tribo-systems. In preliminary testing the limits of lubrication of new tribo-systems for sheet forming production, it is advantageous to use dedicated simulative tribo-tests. This paper studies the influence of tool coatings on deep drawing operations using the Bending Under Tension (BUT) test and also under more severe tribological conditions by adopting the Strip Reduction Test (SRT) to replicate industrial ironing of deep drawn, stainless steel parts. Non-hazardous tribo-systems in form of a double layer Diamond-like coated tool applied under dry condition or with an environmentally friendly lubricant were investigated via emulating industrial process conditions in laboratory tests. Experiments revealed that the double layer coating worked successfully, i.e. with no sign of galling, when it was used with environmentally friendly lubricants, whereas the results were more prone to galling under dry condition.
\end{abstract}

\section{Introduction}

In sheet metal forming applications, friction and lubrication have great importance due to their significant influence on several factors such as metal flow, temperature distribution, workpiece surface quality and tool wear. Recent developments in metal forming industry have made advancements with respect to both the materials and processes of sheet metal forming applications [1]. In order to form tribologically difficult, advanced materials that are in demand in industry, problems are often encountered such as galling, i.e. lubricant film breakdown leading to pick-up of workpiece material on the tool surface and scoring of subsequent workpiece surfaces leading to poor surface quality of the produced part. To prevent these problems, effective tribo-systems are required.

Currently, companies often address these issues by using hazardous chlorinated paraffin oils. These oils enable long runs of industrial processes under severe conditions without lubricant film breakdown due to their efficient boundary lubrication effects. However, the legislation on the application of environmentally hazardous oils is increasingly restrictive [2]. This trend requires the companies to reduce, replace, or even omit the usage of hazardous oils in order to preserve human health and prevent physiochemical and environmental hazards. The development of new environmentally benign tribo-systems has therefore accelerated over the past decade. An alternative 
to standard hazardous lubricants may be to apply a hard Diamond-like Coating (DLC) on the tool surface and perform the stamping operations under dry conditions.

One of the first applications of DLC coatings in stamping operations was developed by Murakawa et al. [3]. A DLC coating was applied on a WC-Co deep drawing die and it was shown that the tool, compared to $\mathrm{TiCN}$ or $\mathrm{CrN}$ coated tools, lasted longer. This increase in durability can be obtained by avoiding adhesion of the sheet material to the die surface. Yet, the drawback of a DLC coating is its low adhesion strength to the tool. This results in the coating peeling off, especially under severe conditions such as high tool/workpiece interface pressure and elevated temperature. An alternative solution to prolong the coating life is to apply a multi-layer structure coating instead of nano-lamination [4]. The multi-layer coating structure and the thickness of each layer can be adjusted to optimize the hardness, load carrying capacity and adhesion between the DLC coating and the tool [5].

Some of the present authors have previously investigated three DLC coating structures: single layer DLC, DLC/Hyperlox ${ }^{\circledR}$ and multi-layer DLC coatings [6]. The tribologically severe strip reduction test, which emulates industrial ironing operations, was selected to evaluate the coatings. It was concluded that the DLC/Hyperlox ${ }^{\circledR}$ coating, illustrated in Fig.1 is a good candidate for dry lubricant applications.

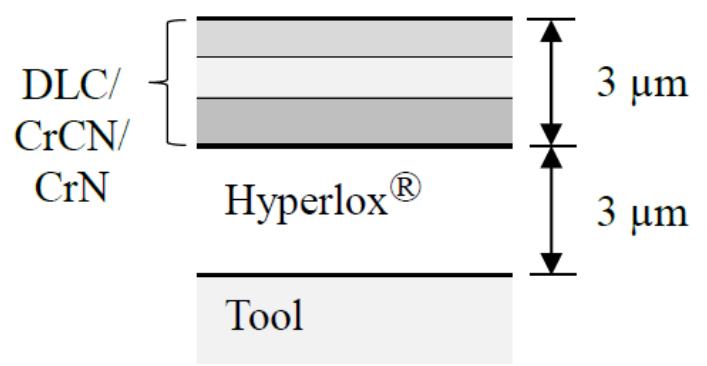

Figure 1. Illustration of DLC/Hyperlox ${ }^{\circledR}$ coating structure [6].

The present study is a continuation of the previous work [6]. The selected double layer coating is used to possibly prevent the occurrence of galling in tribologically severe deep drawing and ironing processes. The specific production conditions are derived from the Danish company Grundfos A/S. The selected simulative tests are Strip Reduction Test (SRT) and Bending Under Tension Test (BUT) to emulate industrial ironing and deep drawing operations, respectively. The test tools are implemented in a universal tribo-tester that can run automatically for multiple strokes and hence better simulate industrial metal forming conditions. Specific production conditions and the method of testing are further described in the following sections.

\section{Case Study}

Industrial Production Case 1. Fig. 2a shows the operation sequence in a progressive tool for manufacturing a bearing plate. The process sequence is deep drawing (1), reverse drawing (2), redrawing (3), blanking (4) and ironing (5). The most critical operation is the ironing process (5), where the thickness of the drawn wall is reduced from $1.35 \mathrm{~mm}$ to $1 \mathrm{~mm}$. The tool has to be replaced every 50,000 strokes because the lubricant film breaks down, which results in workpiece metal pick-up on the punch stem and scoring of the subsequent workpiece surfaces. Hence, the company has an outspoken wish to replace the current tribo-system, thereby reducing the tool cost and increase the productivity.

The workpiece material is $1.5 \mathrm{~mm}$ thick stainless steel EN 1.4301. Tools are made from VANADIS® 4 via powder metallurgy (PM) with a hardness of $61 \mathrm{HRC}$. The ironing punch is coated with AlCrN by Physical Vapor Deposition (PVD). The production speed and the sliding length are 30 strokes/min and $10 \mathrm{~mm}$, respectively. 
Industrial Production Case 2. In the second industrial case, manufacturing of a cup by deep drawing (1) and two re-drawing operations $(2,3)$ in a progressive tool system is performed. The process sequence is illustrated in Fig. $2 b$. The critical operation is the second re-drawing (3), where high normal pressure and temperature increase result in severe tribological conditions. The workpiece material is EN 1.4301 with $1 \mathrm{~mm}$ thickness. The dies and the punches are PM tool steel UHB Vanadis ${ }^{\circledR} 6$ (62 HRC) and PVD coated with TiAlN. The production speed and the sliding length are 40 strokes/min and $20 \mathrm{~mm}$, respectively [7]. Chlorinated paraffin oil, PN226, was recently replaced by an environmentally friendly lubricant. However, the company is interested in omitting the lubricant by introducing new tool materials and coatings.

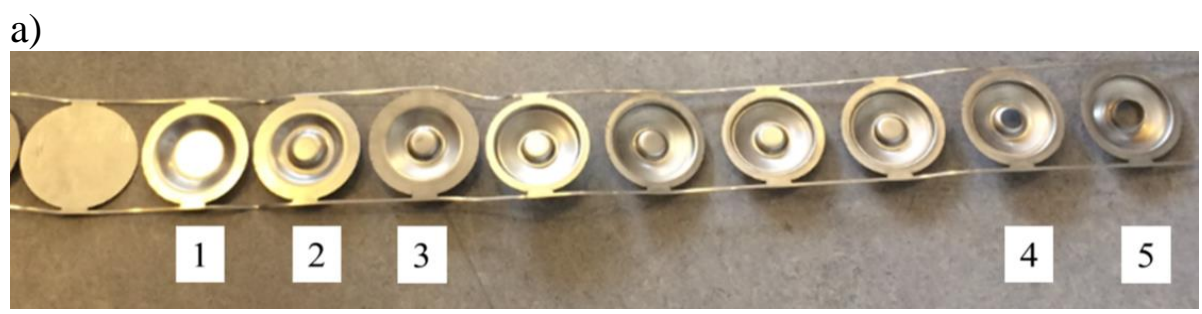

b)

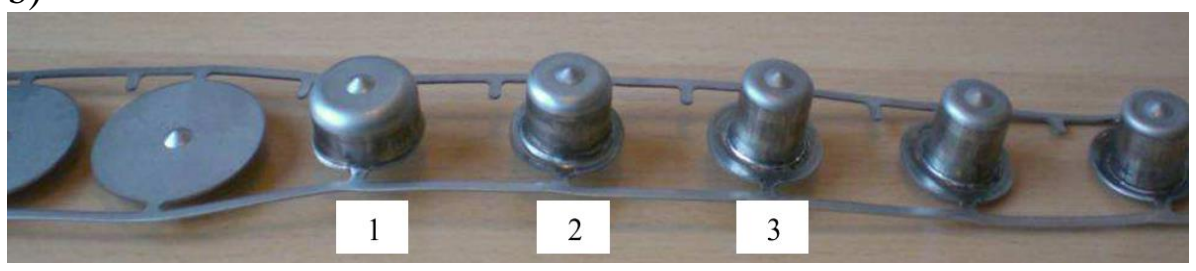

Figure 2. Industrial part produced in a progressive tool a) Case 1 (with process sequence: deep drawing (1), reverse drawing (2), re-drawing (3), punching (4) and ironing (5)) and b) Case 2 (with process sequence: deep drawing (1) and re-drawing $(2,3))$ [8].

\section{Experimental Set-up}

The selected method of simulative testing of the above mentioned critical ironing and deep drawing operations are Strip Reduction Test (SRT) and Bending Under Tension Test (BUT), respectively.

Principles of SRT. SRT is a simulative test in which the process conditions of ironing can be replicated by reducing the thickness of a plane sheet strip. The schematic of the SRT tool used in this study is given in Fig. 3a.

a)

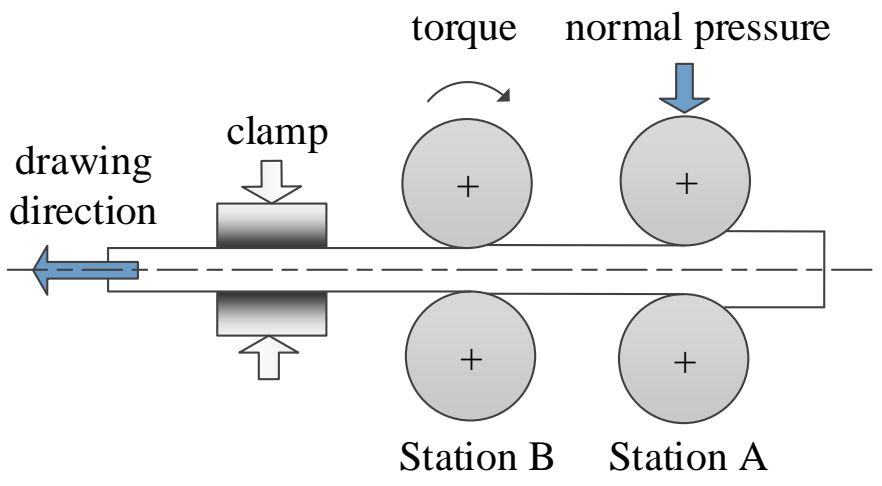

b)

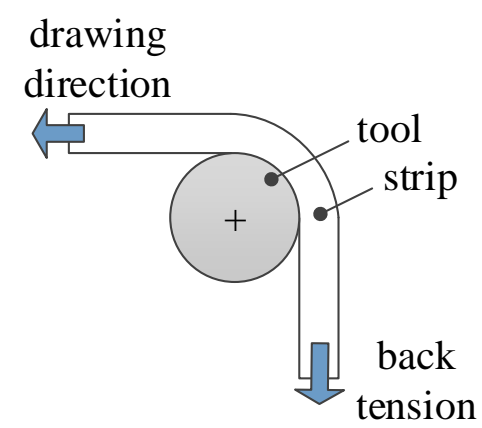

Figure 3. Schematic view of the a) Strip Reduction Test and b) Bending Under Tension Test. 
The set-up allows investigating the performance of tribo-systems in both the forward and backward ironing stroke. The strip is drawn from right to left and the thickness is reduced between two sets of stationary cylindrical tool pins. Station A emulates the forward stoke of an industrial ironing operation. An additional reduction can be introduced at Station B to emulate the backward stroke. The importance of modelling both forward and backward strokes is that in some industrial operating conditions, the elastic contraction of the die before the backward stroke results in severe contact conditions, lubricant film breakdown and/or peeling off of the tool coating and heavy pickup on the tool.

Principles of BUT. The BUT test is used to emulate the process conditions in the die curvature during deep drawing. The strip is bent and slides around a stationary tool pin as shown in Fig. $3 \mathrm{~b}$. Back tension is applied at the end of the strip providing an increase in the normal pressure at the tool/workpiece interface. Front and back tension are measured via a force transducer mounted on the carriage along axis-1 and axis-2, respectively, in Fig. 4. The design also includes a torque transducer along the tool-pin and enables direct torque measurement.

Universal Sheet Tribotester. Both the SRT and BUT tools are operated in the Universal Sheet Tribotester (UST2) as seen in Fig. 4. UST2 is fed by an automatic coil reel and can run multiple strokes. Axis- 1 is the main drawing axis. In SRT, the test is carried out using Axis-3 to ensure the required test load and to reduce the strip thickness, whereas in BUT, Axis-2 is used to control the back tension. Details on installation of test equipment in UST2 and the operation of tests can be found elsewhere [7,9].

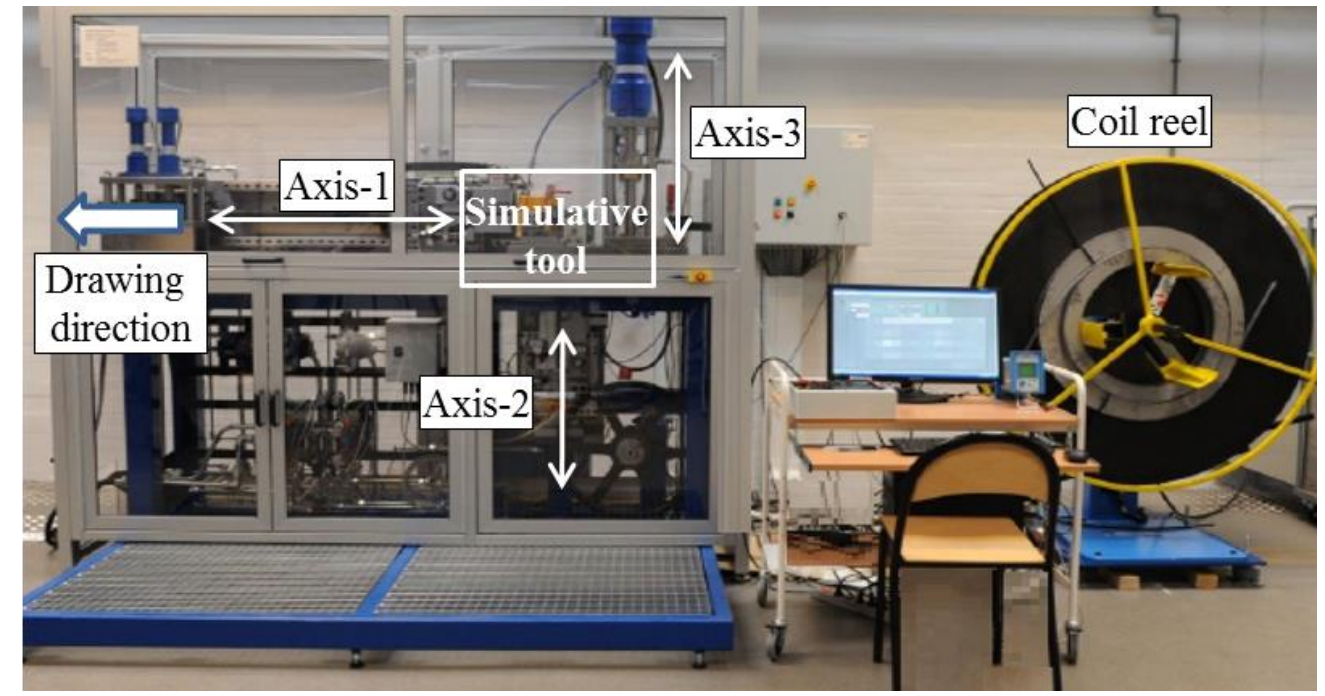

Figure 4. Universal sheet tribo-tester 2 (UST2).

Selected Tribo-systems. After a discussion with the industrial partner, the desired tribo-systems to be further analyzed were determined. They are summarized in Table 1.

For SRT, the coil material of the selected tribo-sytem was EN 1.4301 with dimensions $30 \mathrm{~mm}$ width and $1 \mathrm{~mm}$ thickness. The tool material was Vanadis ${ }^{\circledR} 4$, coated with DLC/Hyperlox ${ }^{\circledR}$. Nonhazardous, plain mineral oil CR5 was applied to both sides of the strip. The reduction at Station A was $20 \%$. The strip was reduced further by $4 \%$ at Station B in order to achieve the final reduction $24 \%$, which is similar to the production line. The sliding length was $10 \mathrm{~mm}$, and the sliding speed was limited to $50 \mathrm{~mm} / \mathrm{s}$. The test aimed to achieve 1500 strokes without the occurrence of lubricant film breakdown with 30 strokes per minute.

In case of BUT, three tribo-sytems with EN 1.4301 and EN 1.4162 (LDX2101) coil materials were tested. EN 1.4301 coil dimensions were $30 \mathrm{~mm}$ width and $1 \mathrm{~mm}$ thickness. The tool radius was $5 \mathrm{~mm}$, and back tension was $200 \mathrm{MPa}$. The tribo-systems 1 and 2 were tested for 1500 strokes. EN 1.4162 coil dimensions were $15 \mathrm{~mm}$ width and $1 \mathrm{~mm}$ thickness. The back tension in case of 
tribo-system 3 was $300 \mathrm{MPa}$ and the aimed total stroke number was 1500 . The BUT test of all three tribo-systems ran with sliding speed $50 \mathrm{~mm} / \mathrm{s}$, and sliding length $20 \mathrm{~mm} / \mathrm{stroke}$. The production rate was 85 strokes per minute. The reason for selecting a high production rate was that the current tribowindow that is used in the production line is able to perform up to 95 strokes per minute [10]. Any new tribo-system must therefore be able to perform at high production rates to be competitive.

Table 1. Investigated tribo-systems using SRT and BUT test set-ups.

\begin{tabular}{|c|c|c|c|c|c|}
\hline $\begin{array}{l}\text { Simulative } \\
\text { Test }\end{array}$ & $\begin{array}{l}\text { Tribo- } \\
\text { system }\end{array}$ & $\begin{array}{c}\text { Workpiece } \\
\text { material }\end{array}$ & Tool material & Tool coating & Lubricant \\
\hline SRT & 1 & EN 1.4301 & Vanadis $^{\circledR} 4$ & DLC/Hyperlox $®$ & CR5 \\
\hline \multirow{3}{*}{ BUT } & 1 & EN 1.4301 & Vanadis ${ }^{\circledR} 4 \mathrm{E}$ & DLC/Hyperlox® & Dry \\
\hline & 2 & EN 1.4301 & Vanadis ${ }^{\circledR} 4 \mathrm{E}$ & DLC/Hyperlox $®$ & CR5 \\
\hline & 3 & EN 1.4162 & Vanadis ${ }^{\circledR} 4 \mathrm{E}$ & DLC/Hyperlox $®$ & CR5 \\
\hline
\end{tabular}

\section{Experimental Results}

Identification of the performance of the tribo-systems can be analysed based on different approaches such as visual inspection of the workpiece and/or tool surface, roughness measurement of the strip surface, measurement of the drawing force, and measurement of the torque.

Fig. 5a shows the experimental evolution of the drawing force and torque with the number of strokes. As seen, the drawing force remains at a constant level, whereas the torque increases gradually to $0.15 \mathrm{Nm}$ at the end of the 1500 strokes. The gradual increase of the torque may suggest the first sign of lubricant film breakdown, which could be identified by running more strokes.

a)

b) Lower tool
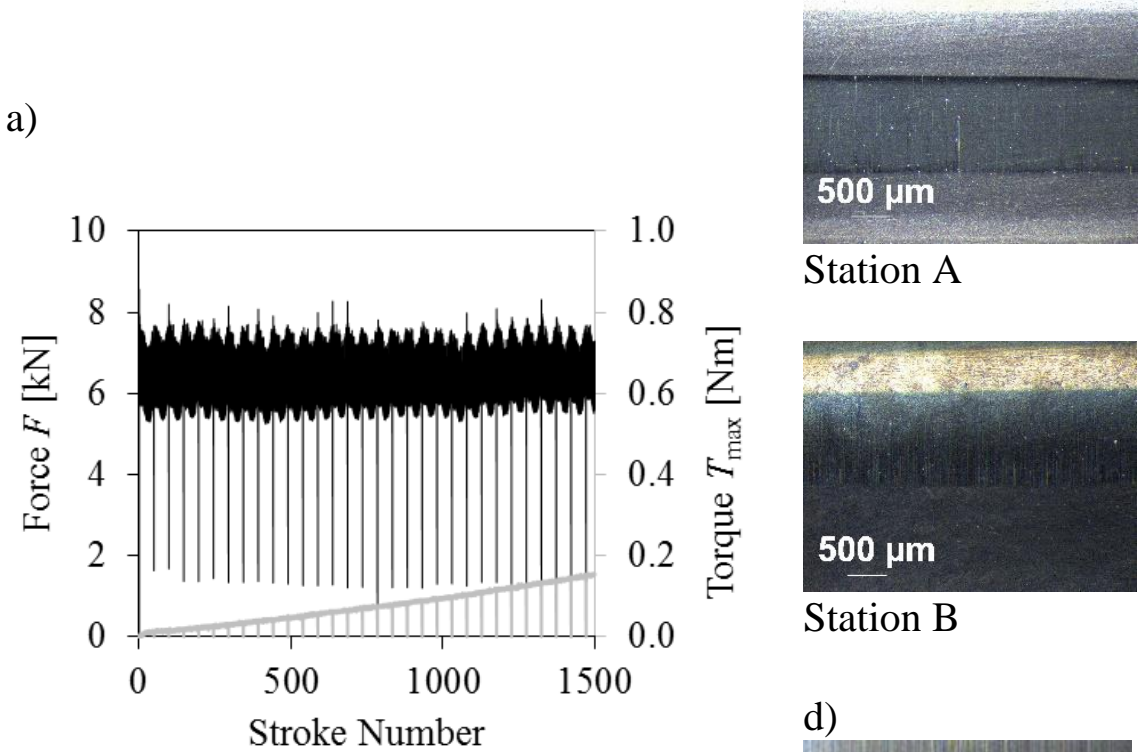

Station A

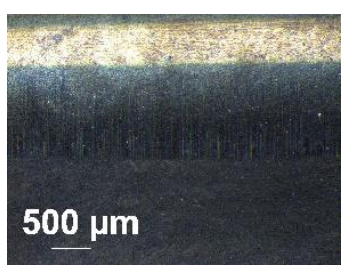

Station B

d)

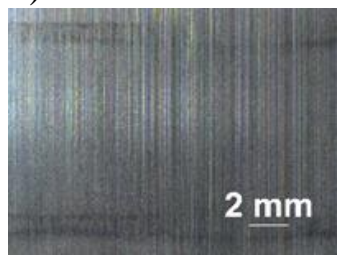

Bottom strip surface c) Upper tool

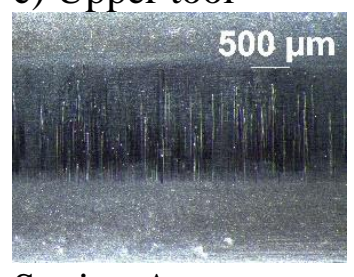

Station A

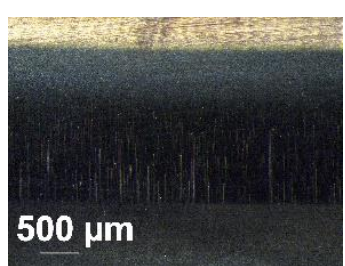

Station B

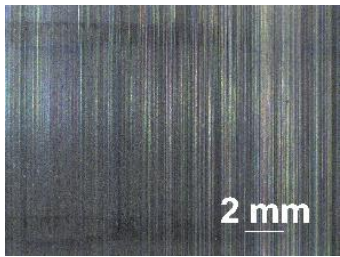

Top strip surface

Figure 5. Results for SRT tribo-system 1 in terms of a) measured torque at Station B (grey) and total drawing force (black) and b-d) LOM images of b) lower tools, c) upper tools and d) strip surfaces. 
For further examination, the images from the lower (Fig. 5b) and upper (Fig. 5c) tool surfaces at both Station A and Station B were taken by light optical microscopy (LOM) after 1500 strokes. The images indicate that the tool surfaces are smooth except light scratches on the upper tool surface at Station A. LOM images taken from the strip surface after the thickness reduction indicate a light adhesive wear in the form of scoring along the strip surface (Fig. 5d). Finally, the results disclose that in spite of the indications towards the onset of lubricant film breakdown, the selected tribosystem runs acceptable for 1500 strokes.

Experimental results of BUT test for tribo-system 1 is given in Fig. 6. For this particular case, no lubricant was used. Both measured torque in Fig. 6a and front tension (drawing force along axis-1) in Fig. $6 \mathrm{~b}$ indicate that the onset of lubricant film breakdown occurs after approximately 700 strokes. LOM images of the tool surface and the workpiece surface after 1500 tests shows clear sign of pick-up (Fig. 6c) and scoring (Fig. 6d). It can therefore be concluded that tribo-system-1 has failed and is unsuitable for the emulated industrial case 2.

a)

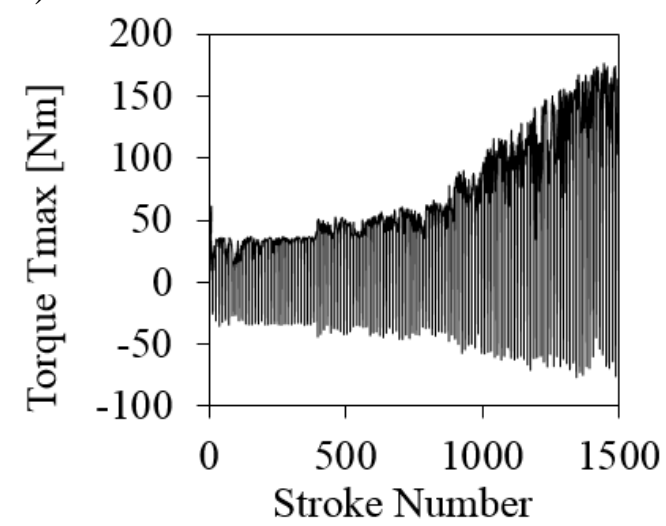

b)

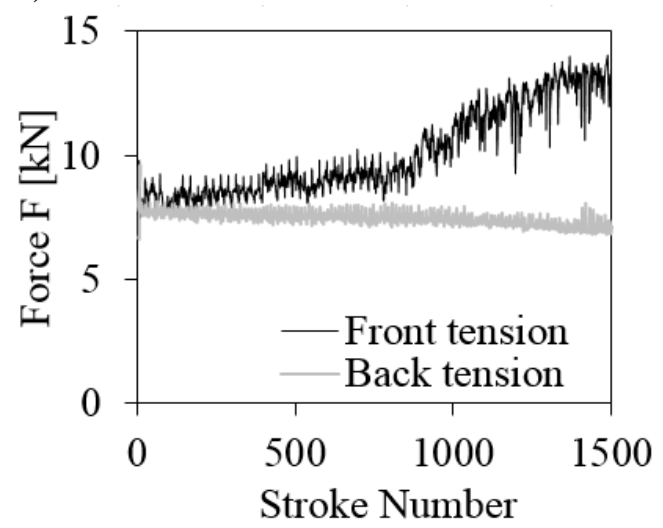

c)

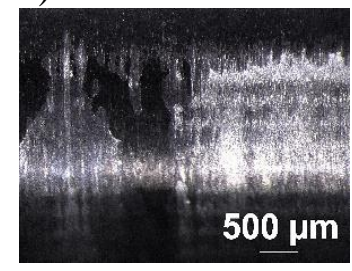

d)

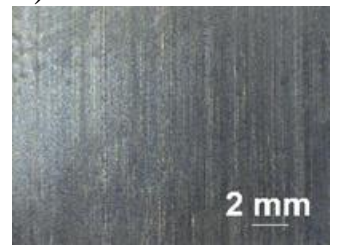

Figure 6. Results for BUT tribo-system 1 in terms of a) measured torque, b) measured forces, and cd) LOM images of c) tool and d) strip surface.
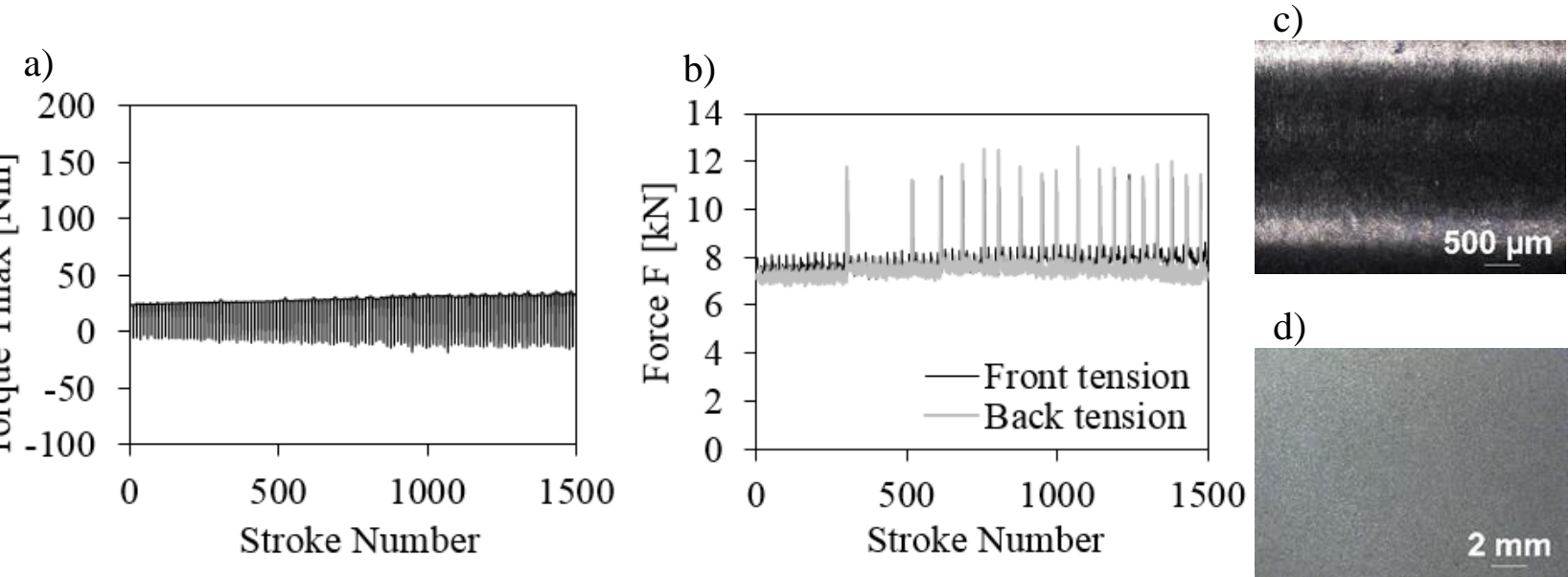

Figure 7. Results for BUT tribo-system 2 in terms of a) measured torque, b) measured forces, and cd) LOM images of c) tool and d) strip surface.

Tribo-system 2 was similar to tribo-system 1 except the test was lubricated. The plain mineral oil, CR5, was applied to both sides of the strip. The results show that both measured torque in Fig. $7 \mathrm{a}$ and drawing force in Fig. 7b are stable. LOM images taken from the tool surface after the test (Fig. 7c) and the lower strip surface (Fig. 7d) show no sign of pick-up or scoring. All in all, tribo- 
system 2 has successfully been applied to the emulated industrial case and can be tested in the production line as an alternative to the running one.

Tribo-system 3 with EN 1.4162 strip material was also tested. CR5 oil was applied to the strip surfaces and the test was run for 1000 strokes. The increase after 500 strokes in the measured torque in Fig. 8a and the drawing force in Fig. 8b reveal lubricant film breakdown. A LOM image taken from the tool surface after the test (Fig. 8c) supports the conclusion that tribo-sytem 3 has failed.

a)

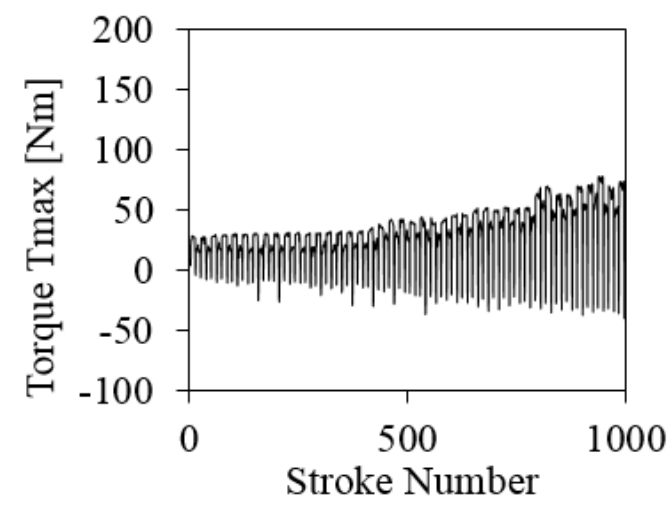

b)

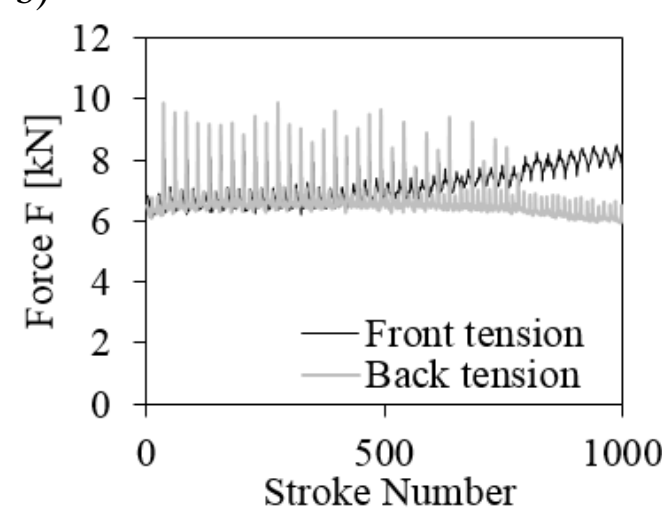

c)

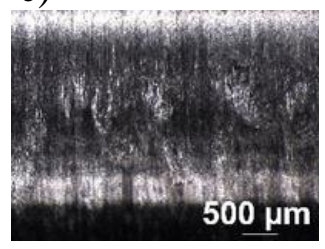

d)

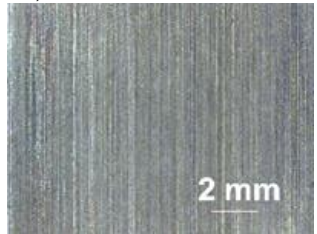

Figure 8. Results for BUT tribo-system 3 in terms of a) measured torque, b) measured forces, and c-d) LOM images of c) tool and d) strip surface..

\section{Summary}

In this study, non-hazardous tribo-systems using DLC/Hyperlox ${ }^{\circledR}$ coated tools under dry conditions or with application of an environmentally friendly lubricant were investigated. The industrial partner has reported two critical production lines, where lubricant film breakdown and galling results in poor surface finish of the produced parts. The critical production stages are deep drawing and ironing in the different production lines. The tribologically critical deep drawing operation in production was emulated by a BUT test. To replicate the industrial ironing of deep drawn parts, the SRT was adopted as laboratory test.

The SRT could be performed until at least 1500 strokes with CR5 as lubricant. Only minor scratches were identified on the tools and the torque increase was neglectable. The tested tribosystem is therefore a promising candidate to be tested as a replacement of the existing tribo-system in the production line. For the three BUT tests, it was possible to draw EN 1.4101 steel with CR5 as lubricant without the occurrence of galling. However, galling occurred when drawing under dry condition. EN 1.4162 could not be drawn without galling, even when lubricating with CR5.

\section{Acknowledgements}

The work is supported by the Danish Council for Independent Research under grant No. DFF 4005-00130. The authors gratefully acknowledge the help from CemeCON Scandinavia A/S for providing the double layer DLC coating.

\section{References}

[1] N. Bay, 2011, Trends and Vision in Metal Forming Tribology, 10th International Conference on Technology of Plasticity, Lyngby, Denmark. (2011) pp. 15-26. 
[2] European Comission, Regulation (EC) 1907/2006 of the European Parliament and of Teh Council of 18 December 2006 - REACH, Off. J. Eur. Union, pp. 396-849 [Online]. Available: http://eur-lex.europa.eu/legal-content/EN/TXT/PDF/?uri=CELEX:32006R1907\&from=en.

[3] M. Murakawa, N. Koga, T. Kumagai, Deep-Drawing of Aluminium Sheets without Lubricant by Use of Dimond-like Carbon Coated Dies, Surf. Coatings Technol. $76-77$ (1-3) (1995) pp. 553558.

[4] T. Aizawa, E. Iwamura, K. Itoh, Nano-Lamination in Amorphous Carbon for Tailored Coating in Micro-Dry Stamping of AISI-304 Stainless Steel Sheets, Surf. Coatings Technol. 203(5-7) (2008) pp. 794-798.

[5] J. Vetter, 60years of DLC Coatings: Historical Highlights and Technical Review of Cathodic Arc Processes to Synthesize Various DLC Types, and Their Evolution for Industrial Applications, Surf. Coatings Technol. 257 (2014) pp. 213-240.

[6] M.H. Sulaiman, P. Christiansen, P., N. Bay, A Study of DLC Coatings for Ironing of Stainless Steel, 36th Int. Deep Draw. Res. Gr (2017).

[7] E. Ceron, N. Bay, A Methodology for off-Line Evaluation of New Environmentally Friendly Tribo-Systems for Sheet Metal Forming, CIRP Ann. - Manuf. Technol. 62(1) (2013) pp. 231-234.

[8] N. Bay, E. Ceron, Off-Line Testing of Tribo-Systems for Sheet Metal Forming Production, Adv. Mater. Res. 966-967 (2014) pp. 3-20.

[9] E. Üstünyagiz, C.V. Nielsen, P. Christiansen, P.A.F. Martins, N. Bay, Continuous Strip Reduction Test Simulating Tribological Conditions in Ironing, Procedia Eng. 207 (2017) pp. 22862291.

[10]E. Ceron, New Tribo-Systems for Sheet Metal Forming of Advanced High Strength Steels and Stainless Steels, PhD Thesis, Denmark Technical University (2013) pp. 108-109. 